\title{
Research Article \\ Recent Changes of Some Observed Climate Extreme Events in Kano
}

\author{
Imole Ezekiel Gbode, Akintomide Afolayan Akinsanola, and Vincent Olanrewaju Ajayi \\ Department of Meteorology, Federal University of Technology Akure, PMB 704, Akure, Ondo State, Nigeria \\ Correspondence should be addressed to Imole Ezekiel Gbode; gbodeimoleayo@yahoo.com
}

Received 2 July 2014; Revised 3 November 2014; Accepted 1 January 2015

Academic Editor: Thomas Reichler

Copyright (C) 2015 Imole Ezekiel Gbode et al. This is an open access article distributed under the Creative Commons Attribution License, which permits unrestricted use, distribution, and reproduction in any medium, provided the original work is properly cited.

\begin{abstract}
Observed rainfall and temperature data for the period 1960-2007 were used to examine recent changes of extreme climate over Kano, located in the Sahelian region of Nigeria. The RClimDex software package was employed to generate nine important climate indices as defined by the Expert Team on Climate Change Detection, Monitoring and Indices (ETCCDMI). For the entire period, the results show a warming trend, an increased number of cool nights, more warm days, and a strong increase in the number of warm spells. The rainfall indices show a slight increase in annual total rainfall, a decrease in the maximum number of consecutive wet days, and a significant increase in the number of extremely wet days. Such changes in climate may result in an increasing demand for domestic energy for cooling and a higher evaporation rate from water bodies and irrigated crop. These findings may give some guidance to politicians and planners in how to best cope with these extreme weather and climate events.
\end{abstract}

\section{Introduction}

Extreme weather and climate events are currently bone of contention of higher scientific and societal interest. Interest on this topic has been raised by relevant scientific communities, most especially climatological branches that assess climate change (e.g., observational, modeling, adaptation, and impact sectors). The issue has been addressed recently by the Intergovernmental Panel on Climate Change [1] in the Special Report on Extremes (SREX). This has provided the most comprehensive global review and assessment on the relation between climate extremes, their impacts, and the strategies to manage associated perils.

Quite a number of issues, however, constrain our current understanding and scientific confidence in the observed changes in extremes. Among others, availability and accessibility of long-term and high quality climate series at the relevant time scales for assessing extremes (e.g., daily and subdaily) is one of the most serious gaps, particularly over some regions of the world (often called climate-data-sparse regions), such as most of West Africa. The availability of climate series is also limited temporally, since for most of the world the length of digitized daily climate series (e.g., for temperature and precipitation) only goes back in time to the mid-20th century and for many regions is restricted to the 1970s onwards. In addition, there are also concerns regarding the quality and homogeneity of the available series, which could compromise the robustness of assessed changes. Many countries also restrict access to their higher temporal resolution time-series. In short, the quality and quantity of accessible climate series still limit our understanding of the observed changes in climate extremes, particularly over data-sparse regions [2].

Some international groups have made major efforts to advance knowledge of global changes in climate extremes and to promote the recovery and development of climate data (i.e., ensuring data quality and homogeneity) over data-sparse regions. However, the World Meteorological Organization, through the Climate Variability and Predictability (WMO/ CLIVAR) Expert Team on Climate Change Detection, Monitoring Indices (ETCCDMI), coordinated a series of workshops in different regions of the world to help scientists and national experts discuss and quality control climate data. They have also promoted the analysis and monitoring of extremes around the world through organizing regional workshops in data-sparse regions that have involved scientists from National Meteorological and Hydrological Services (NMHS) as part of ETCCDMI's two-pronged approach [3]. 


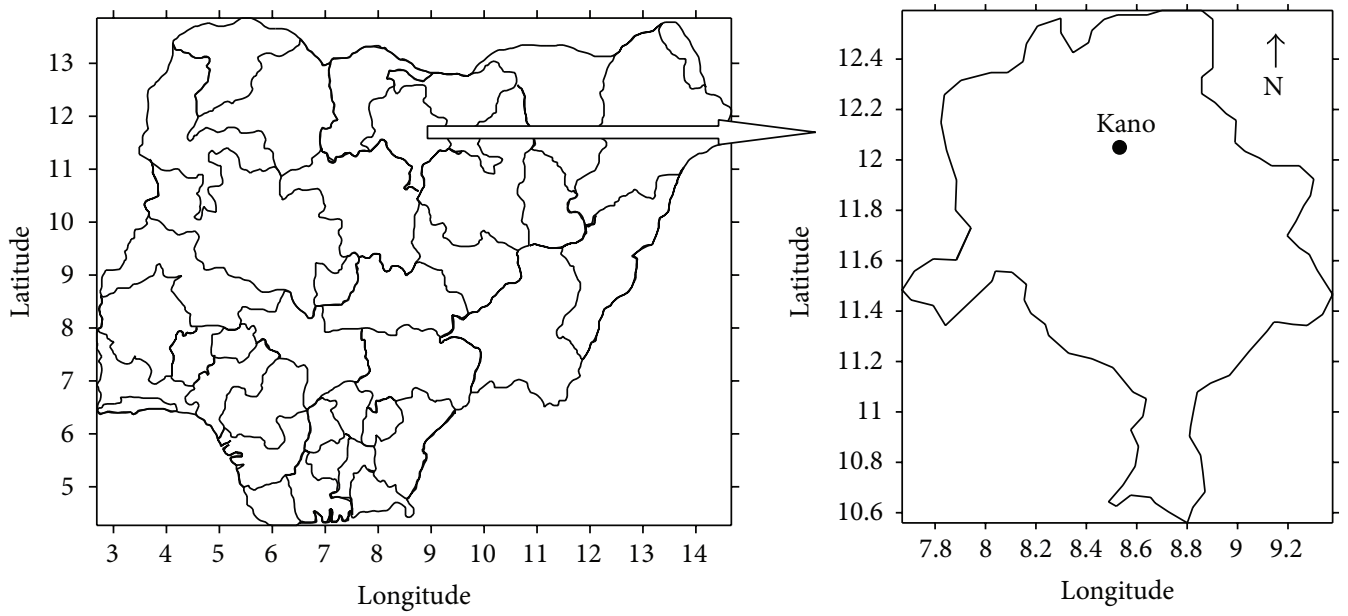

FIgURE 1: Map of Nigeria showing the projection of Kano.

Some regional analyses were thus undertaken for the understanding of climate extreme and trends [4-7]. Recent studies in Africa, when analyzing daily climate in terms of trends and extreme indices, revealed some significant increase and decrease in annual precipitation, increases in longest wet spells, and increases in high daily precipitation amounts and average rainfall intensity [8-10]. Minimum temperature was found to have increased faster than maximum temperature, thus contributing to narrow the diurnal temperature range $[11,12]$.

The Sahelian region of West Africa is one of the most vulnerable zones to climate change [13]. Since the devastating drought of 1970 and early 1980s Sahelian region has been an area of intense rainfall and temperature studies [14, 15], hence the need of this study to assess recent changes in the intensity of extreme daily rainfall and temperature in Kano located in the Sahelian region of Nigeria. Being a data sparse region [2], Kano was used in this study because of long-term continuous record of rainfall and temperature data.

\section{Methods}

2.1. Study Region. The study was conducted over Kano (Figure 1), located in the Sahelian region of Nigeria with average daily and annual rainfall of $5.6 \mathrm{~mm}$ and $750 \mathrm{~mm}$, respectively. The mean annual lower and upper thresholds of minimum and maximum temperatures are comprised between 14.5 and $23.2^{\circ} \mathrm{C}$ for minimum temperature and 30.6 and $38^{\circ} \mathrm{C}$ for the maximum temperature (Figure 3 ). The region has a single rainfall peak (Figure 2), with the onset of the rains between May and July and cessation between September and October $[16,17]$. The monthly distribution of temperature has double peaks with one the peaks in April and another in October. To ascertain the reliability of the data used, statistical analysis comparing the station rainfall data with that of the Global Precipitation Climatology Centre (GPCC) data [18] and the station temperature data with the Climate Research Unit (CRU) data [19] was carried out where

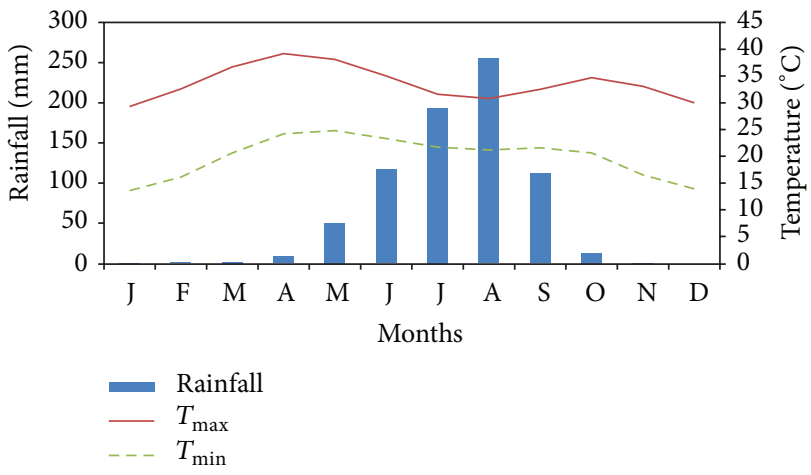

FIGURE 2: Seasonal circle of rainfall and temperature over Kano.

the Root Mean Square Errors (RMSEs) of 6.05 and 4.87 were obtained for the rainfall and temperature data, respectively.

2.2. Rainfall and Temperature Data. Daily observations of rainfall and temperature data obtained from the archive of the Nigerian Meteorological Agency (NIMET) for the period 1960-2007 were used in this study. Due to the quality of NIMET data, it has been employed to perform researches by numerous studies $[8,20,21]$, and so forth. The data obtained in this study was split into two periods, base period (1960-1990) and recent period (1991-2007), in order to assess observed changes of extreme climate over the station. The data was quality controlled using the RClimDex software package [22] which could be freely downloaded from the ETCCDMI website [23]. In the data quality control subroutine unrealistic data, (i) days with negative or greater than $500 \mathrm{~mm}$ rainfall amount, (ii) days with minimum temperature equal to or greater than maximum temperature, and (iii) minimum and maximum temperatures greater than 6 standard deviations from the long-term (full dataset) mean value were detected and removed. Also in the quality control process each time series was tested to ensure homogeneity in the 


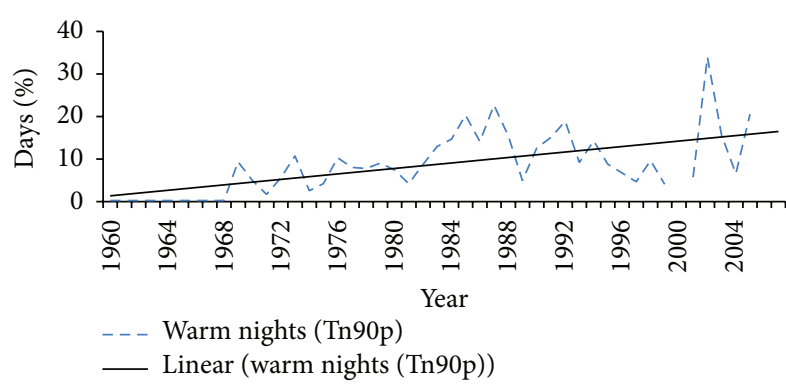

(a)

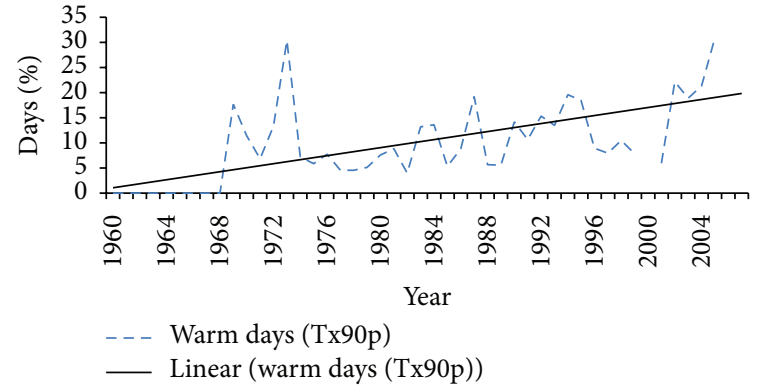

(b)

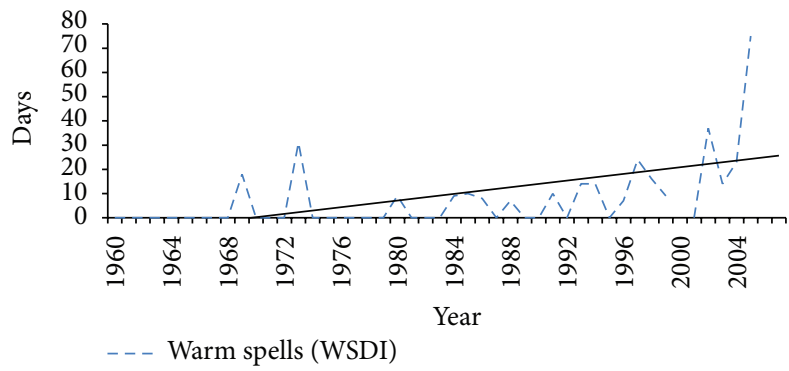

(c)

FIGURE 3: Changes of the percentage of (a) warm nights (Tn90p), (b) warm days (Tx90p), and the (c) arm spell days (WSDI) from 1960 to 2007.

whole dataset. The erroneous observations (i.e., the unrealistic data) were replaced with a code (-99.9) which is recognized as missing data by the RClimDex software package to avoid errors in the computation. After ensuring these measures the station data was more than $80 \%$ consistent to further execute the study.

2.3. Climate Indices. According to $[3,24]$ characterizing the frequency, intensity, and duration of climate extremes can be done by calculating climates indices based on daily time series of temperature and rainfall. International research groups such as the Expert Team on Climate Change Detection Monitoring Indices (ETCCDMI) have undertaken a set of regional analyses for understanding climate extremes and trends $[3,4,8,25]$. Out of the 27 core indices computed on the daily basis by RClimDex, 9 were selected and considered most relevant for our study region as shown in Table 1.

2.4. Trend Analysis. In the study, statistical analyses were done over the last 48 years since 1960 including the climatological base period of 1960-1990 as defined in the source code of the RClimDex. Plots and tables of trends for the period 1960-2007 for some selected indices were generated using the RClimDex, a developing script in R open source software. To determine the significance of the trends, Student $t$-test was performed and the resulting $P$ value, which now serves as a criterion to define the class boundary, was used to analyze the null hypothesis that the trend is equal to 0 . The trend for each index was considered significant when found $\leq 0.05$ and less significant above this interval.

\section{Results}

3.1. Temperature Indices. Temperature indices show a warming trend in Kano during the period from 1960 to 2007 (Table 2). However, from Table 2, the station shows a positive slope of 0.23 for the frequency of cool nights, meaning that the nights have become colder though not as high as the warm nights with a positive slope of 0.322 . Warm days and warm spells have also become more frequent with the latter showing a very significant increase with a positive slope of 0.687 . The diurnal temperature range shows a less significant positive trend of 0.006 . Both maximum and minimum temperatures have increased during the period with indication that the warming has been faster with maximum temperature. Figure 3 shows that the warming is steady and consistent. Slight increase in cool nights and cool days was observed but warm nights, warm days, and warm spells increased significantly. In Table 3, the frequency of cool nights was the same as that of warm nights in the recent period with a very high frequency of warm spell days. In Table 4, the percentage of cool nights between the two periods is quite minimal as compared to warm nights. Also shown in Table 4 is high percentage difference of 0.80 and $4.33 \%$ for warm days and warm spells, respectively, between the two periods.

3.2. Rainfall Indices. Trend in rainfall indices is highly variable compared to temperature. There was a slight increase in annual total rainfall and decrease in maximum number of consecutive wet days as observed in the region (Figures 4(b) and 4(c)), whereas from Figure 4(d), Table 5, the accumulated rainfall of extremely wet days shows an increasing trend. It can also be seen from Table 5 that the maximum 5-day rainfall 
TABLE 1: Summary of the temperature and rainfall indices used in the study: Tn and Tx are daily minimum and maximum temperature, respectively.

\begin{tabular}{lclll}
\hline Element & Index & Descriptive name & Definition & Units \\
\hline Rainfall & PRCPTOT & Annual total rainfall & Annual total PRCP in wet days (RR $\geq 1 \mathrm{~mm})$ & Mm \\
Rainfall & RX5day & Maximum 5-day precipitation & Maximum 5-day precipitation & Mm \\
Rainfall & CWD & Consecutive wet days & Maximum number of consecutive wet days & Days \\
Rainfall & R99p & Extremely wet days & Annual total PRCP when RR $>$ 99th percentile & $\%$ \\
Tn & Tn10p & Cool night frequency & Percentage of days with TN $<$ 10th percentile of 1960-2007 \\
Tn & Tn90p & Warm night frequency & Percentage of days with TN $>90$ th percentile of 1960-2007 & $\%$ \\
Tx & Tx10p & Cool day frequency & Percentage of days with TX < 10th percentile of 1960-2007 & $\%$ \\
Tx & Tx90p & Warm day frequency & Percentage of days with TX $>90$ th percentile of 1960-2007 & Annual count of days with at least 6 consecutive days with TX $>90$ th \\
Tx & WSDI & Warm spells & Dercentile of 1960-2007 & \\
\hline
\end{tabular}

TABLE 2: Observed trends in some temperature indices in Kano from 1960 to 2007.

\begin{tabular}{llcc}
\hline & Indices & Trends & $P$ values \\
\hline (a) & Cool nights (Tn10p) & 0.23 & 0.007 \\
(b) & Warm nights (Tn90p) & 0.322 & 0.000 \\
(c) & Cool days (Tx10p) & 0.221 & 0.000 \\
(d) & Warm days (Tx90p) & 0.399 & 0.000 \\
(e) & Warm spells (WSDI) & 0.687 & 0.000 \\
(f) & Diurnal temperature range (DTR) & 0.006 & 0.303 \\
\hline
\end{tabular}

TABLE 3: Summary of the daily temperature indices between the base (1961-1990) and recent (1991-2007) period.

\begin{tabular}{|c|c|c|c|}
\hline \multirow{2}{*}{ Indices } & \multicolumn{2}{|c|}{ Period } & \multirow{2}{*}{ Unit } \\
\hline & 1960-1990 & 1991-2007 & \\
\hline Cool nights & 211 & 150 & Days \\
\hline Warm nights & 203 & 150 & Days \\
\hline Cool days & 210 & 151 & Days \\
\hline Warm days & 178 & 147 & Days \\
\hline Warm spell & 92 & 319 & Days \\
\hline
\end{tabular}

amount, total annual rainfall, and the amount of rainfall during extremely wet days are on the increase.

\section{Discussion}

Studies in other regions of the world have shown similar tendencies in temperature indices as found in our study. For example, [26] in their study found a general warming trend throughout the West African Sahel region during the period from 1960 to 2010, a negative trend in the number of cool nights, and more frequent warm days and warm spells. Also they found that the trend in rainfall related indices was not as uniform as the ones in temperatures with decreased tendency of annual total rainfall and maximum number of consecutive wet days within the study period and that the accumulated rainfall of extremely wet days indicated a positive trend in most locations of the region. Results in this study show all temperature indices except for the diurnal temperature trend
TABLE 4: Summary of the daily temperature indices between the base (1961-1990) and recent (1991-2007) period.

\begin{tabular}{lcccc}
\hline \multirow{2}{*}{ Indices } & \multicolumn{2}{c}{ Period } & \multirow{2}{*}{ Difference } & Unit \\
& $1960-1990$ & $1991-2007$ & & \\
\hline Cool nights & 1.86 & 2.42 & 0.55 & $\%$ \\
Warm nights & 1.79 & 2.42 & 0.62 & $\%$ \\
Cool days & 1.85 & 2.43 & 0.58 & $\%$ \\
Warm days & 1.57 & 2.37 & 0.80 & $\%$ \\
Warm spell & 0.81 & 5.14 & 4.33 & $\%$ \\
\hline
\end{tabular}

TABLE 5: Observed trends in some temperature indices in Kano from 1960 to 2007.

\begin{tabular}{lclcc}
\hline & Indices & Description & Trends & $P$ values \\
\hline (a) & PRCPTOT & Annual total rainfall & 0.486 & 0.793 \\
(b) & RX5day & Maximum 5-day precipitation & 0.221 & 0.454 \\
(c) & CWD & Consecutive wet days & -0.047 & 0.006 \\
(d) & R99p & Extremely wet days & 0.659 & 0.344 \\
\hline
\end{tabular}

that has significant warming trend over the station during the considered period with increased number of cool nights, more frequent warm days and warm spells corroborating recent findings in some parts of Africa including Nigeria [8].

However, all the rainfall indices showed slight increase in annual total rainfall $(0.486 \mathrm{~mm}$ per year $)$, decrease in maximum number of consecutive wet days $(-0.047$ days per year), and increase in extremely wet days (0.659 days per year). These remarkable changes are not different from that obtained and reported globally in some regions of the world [27]. These observed changes in climate may result in an increasing demand for domestic energy for cooling and a higher evaporation rate from water bodies and irrigated crop.

\section{Conclusion}

The study showed that temperature indices over Kano indicate warming trend since 1960, while for the rainfall indices there were slight increase in annual total rainfall, decrease in maximum number of consecutive wet days, and increasing 


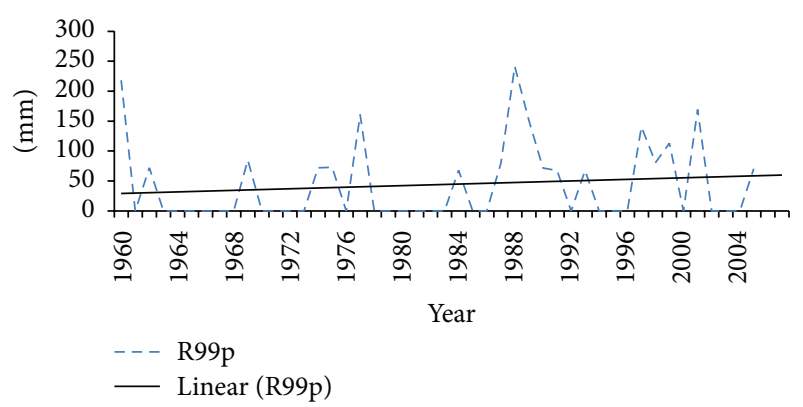

(a)

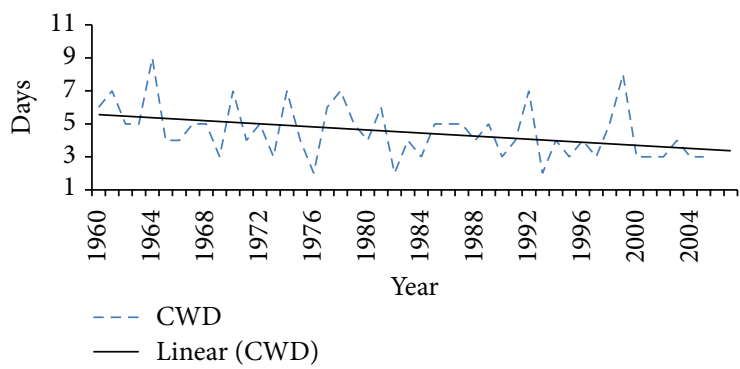

(c)

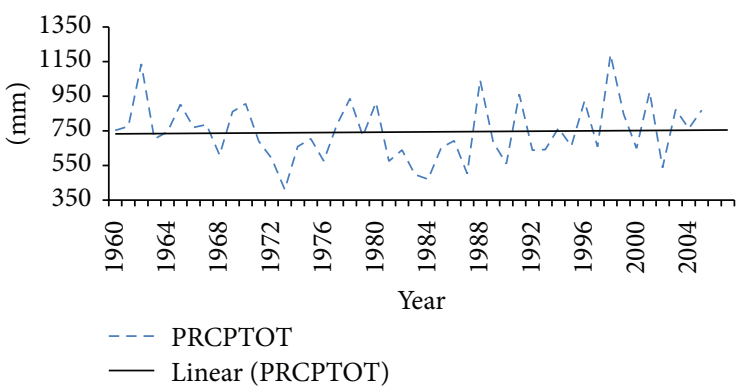

(b)

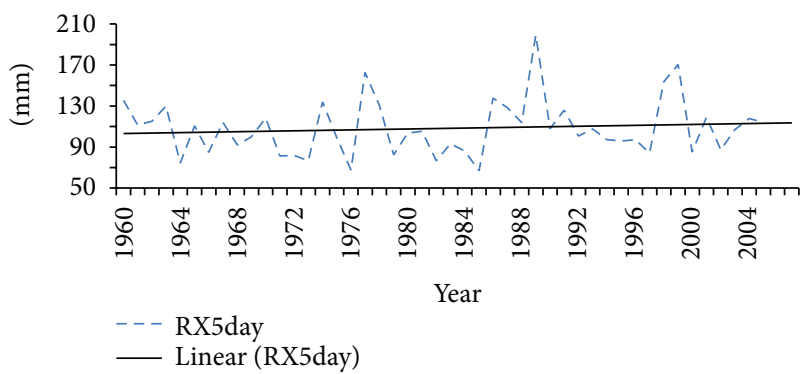

(d)

FIGURE 4: Trends of (a) extremely wet days, (b) annual total rainfall, (c) consecutive wet days, and (d) maximum 5-day precipitation.

trend of extremely wet days. Similar observed trend has raised eye brows and has become bone of contention globally as it has serious implications on the economy. This inevitable climate effect which needs to be adapted to may cost this region expending on some resources. The observed changes may result in an increasing demand for domestic energy for cooling and a higher evaporation rate from water bodies and irrigated crops which is a major practice in this region, and a lower performance of agricultural crops and livestock. It is therefore paramount for policy makers to ensure investment and promotion of more energy efficient infrastructure and domestic appliances as well as encouraging low cost and environmentally friendly energy production systems in order to cope with these extreme weather and climate events.

\section{Conflict of Interests}

The authors declare that there is no conflict of interests regarding the publication of this paper.

\section{Acknowledgments}

The authors acknowledge the Nigerian Meteorological Agency, Global Precipitation Climatology Centre, and the Climate Research Unit for the use of their data for this work. The authors also thank the R foundation and CCI/CLIVAR/ JCOMM Expert Team on Climate Change Detection and Indices (ETCCDI) for the use of their software for analysis. The effort of anonymous reviewers is also acknowledged.

\section{References}

[1] Intergovernmental Panel on Climate Change, "Managing the risks of extreme events and disasters to advance climate change adaptation," in A Special Report of Working Groups I and II of the Intergovernmental Panel on Climate Change, C. B. Field, V. Barros, T. F. Stocker et al., Eds., p. 582, Cambridge University Press, Cambridge, UK, 2012.

[2] K. E. Trenberth, P. D. Jones, P. Ambenje et al., "Observations: surface and atmospheric climate change," in Climate Change 2007: The Physical Science Basis. Contribution of Working Group I to the Fourth Assessment Report of the Intergovernmental Panel on Climate Change, S. Solomon, D. Qin, M. Manning, and etal, Eds., pp. 235-336, Cambridge University Press, Cambridge, UK, 2007.

[3] T. C. Peterson and M. J. Manton, "Monitoring changes in climate extremes: a tale of international collaboration," Bulletin of the American Meteorological Society, vol. 89, no. 9, pp. 12661271, 2008.

[4] D. R. Easterling, L. V. Alexander, A. Mokssit, and V. Detemmerman, "CCI/CLIVAR workshop to develop priority climate indices," Bulletin of the American Meteorological Society, vol. 84, no. 10, pp. 1403-1329, 2003.

[5] E. Aguilar, T. C. Peterson, P. R. Obando et al., "Changes i precipitation and temperature extremes in Central America and northern South America, 1961-2003," Journal of Geophysical Research D: Atmospheres, vol. 110, no. 23, Article ID D23107, pp. $1-15,2005$.

[6] L. A. Vincent, T. C. Peterson, V. R. Barros et al., "Observed trends in indices of daily temperature extremes in South America 1960-2000," Journal of Climate, vol. 18, no. 23, pp. 50115023, 2005.

[7] M. R. Haylock, T. C. Peterson, L. M. Alves et al., "Trends in total and extreme South American rainfall in 1960-2000 and links 
with sea surface temperature," Journal of Climate, vol. 19, no. 8, pp. 1490-1512, 2006.

[8] M. New, B. Hewitson, D. B. Stephenson et al., "Evidence of trends in daily climate extremes over southern and west Africa," Journal of Geophysical Research D: Atmospheres, vol. 111, no. 14, 2006.

[9] L. V. Alexander, X. Zhang, T. C. Peterson et al., "Global observed changes in daily climate extremes of temperature and precipitation," Journal of Geophysical Research D: Atmospheres (19842012), vol. 111, no. D5, 2006.

[10] J. M. Collins, “Temperature variability over Africa," Journal of Climate, vol. 24, no. 14, pp. 3649-3666, 2011.

[11] D. R. Easterling, B. Horton, P. D. Jones et al., "Maximum and minimum temperature trends for the globe," Science, vol. 277, no. 5324, pp. 364-367, 1997.

[12] J. Caesar, L. Alexander, and R. Vose, "Large-scale changes in observe daily maximum and minimum temperatures: creation and analysis of a new gridded data set," Journal of Geophysical Research D: Atmospheres, vol. 111, no. 5, Article ID D05101, 2006.

[13] S. T. Kandji, L. Verchot, and J. Mackensen, Climate Change and Variability in the Sahel Region: Impacts and Adaptation Strategies in the Agricultural Sector, World Agroforestry Centre, 2006.

[14] Y. L'Hôte, G. Mahé, B. Somé, and J. P. Triboulet, "Analysis of a Sahelian annual rainfall index from 1896 to 2000; the drought continues," Hydrological Sciences Journal, vol. 47, no. 4, pp. 563$572,2002$.

[15] S. E. Nicholson, "Sub-saharan rainfall in the years 1976-80: evidence of continued drought," Monthly Weather Review, vol. 111, no. 8, pp. 1646-1654, 1983.

[16] M. V. K. Sivakumar, "Predicting rainy season potential from the onset of rains in Southern Sahelian and Sudanian climatic zones of West Africa," Agricultural and Forest Meteorology, vol. 42, no. 4, pp. 295-305, 1988.

[17] P. Camberlin and M. Diop, "Application of daily rainfall principal component analysis to the assessment of the rainy season characteristics in Senegal," Climate Research, vol. 23, no. 2, pp. 159-169, 2003.

[18] U. Schneider, A. Becker, P. Finger, A. Meyer-Christoffer, B. Rudolf, and M. Ziese, "GPCC Full Data Reanalysis Version 6.0 (at $0.5^{\circ}, 1.0^{\circ}, 2.5^{\circ}$ ): Monthly Land-Surface Precipitation from Rain-Gauges built on GTS-based and Historic Data," 2011.

[19] http://www.cru.uea.ac.uk/data.

[20] B. E. Omogbai, "An empirical prediction of seasonal rainfall in Nigeria," Journal of Human Ecology, vol. 32, no. 1, pp. 23-27, 2010.

[21] J. A. Omotosho, A. A. Balogun, and K. O. Ogunjobi, "Predicting monthly and seasonal rainfall, onset and cessation of the rainy season in West Africa using only surface data," International Journal of Climatology, vol. 20, pp. 865-880, 2000.

[22] X. Zhang and F. Yang, RClimDex (1.0) User Manual, Climate Research Branch Environment, Ontario, Canada, 2004.

[23] http://etccdi.pacificclimate.org/software.shtml.

[24] T. R. Karl, N. Nicholls, and A. Ghazi, "CLIVAR/GCOS/WMO workshop on indices and indicators for climate extremes workshop summary," in Weather and Climate Extremes, pp. 3-7, Springer, Amsterdam, The Netherlands, 1999.

[25] L. A. Vincent and É. Mekis, "Changes in daily and extreme temperature and precipitation indices for Canada over the twentieth century," Atmosphere-Ocean, vol. 44, no. 2, pp. 177-193, 2006.
[26] L. Mouhamed, S. B. Traore, A. Alhassane, and B. Sarr, "Evolution of some observed climate extremes in the West African Sahel," Weather and Climate Extremes, vol. 1, pp. 19-25, 2013.

[27] Intergovernmental Panel on Climate Change, "Climate change 2007 synthesis report," in Contribution of Working Group I, II and III to the Fourth Assessment Report of the Intergovernmental Panel on Climate Change, K. Pachauri and A. Reisinger, Eds., IPCC, Geneva, Switzerland, 2007. 

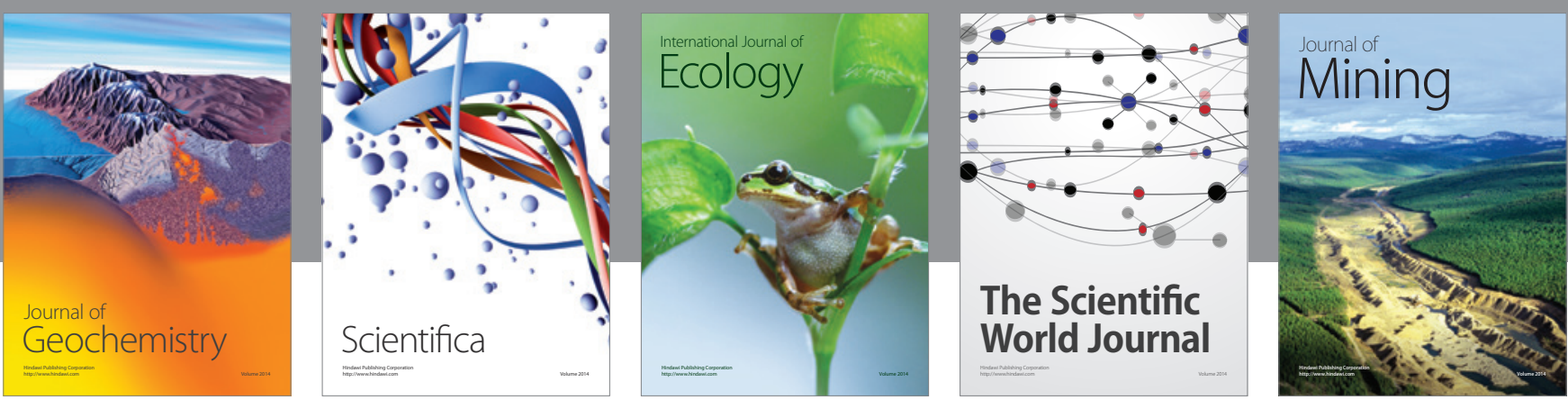

The Scientific World Journal
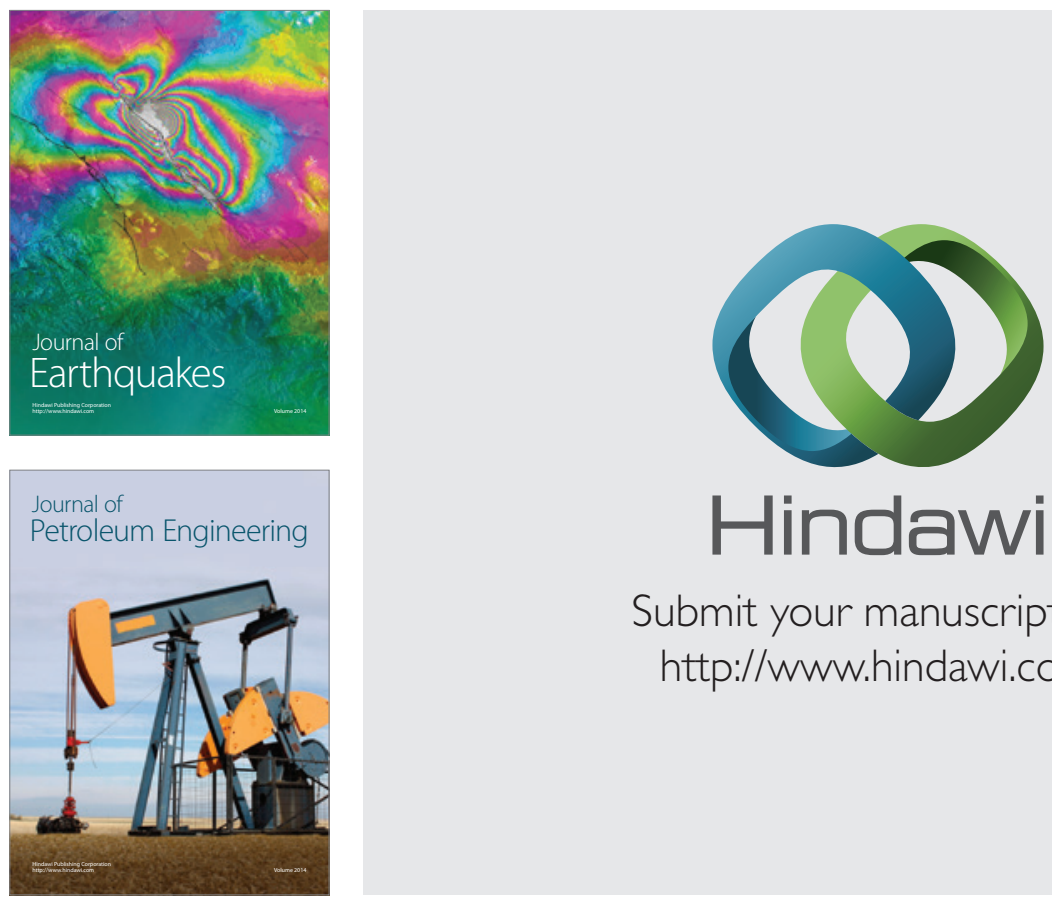

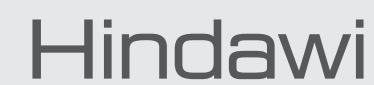

Submit your manuscripts at

http://www.hindawi.com
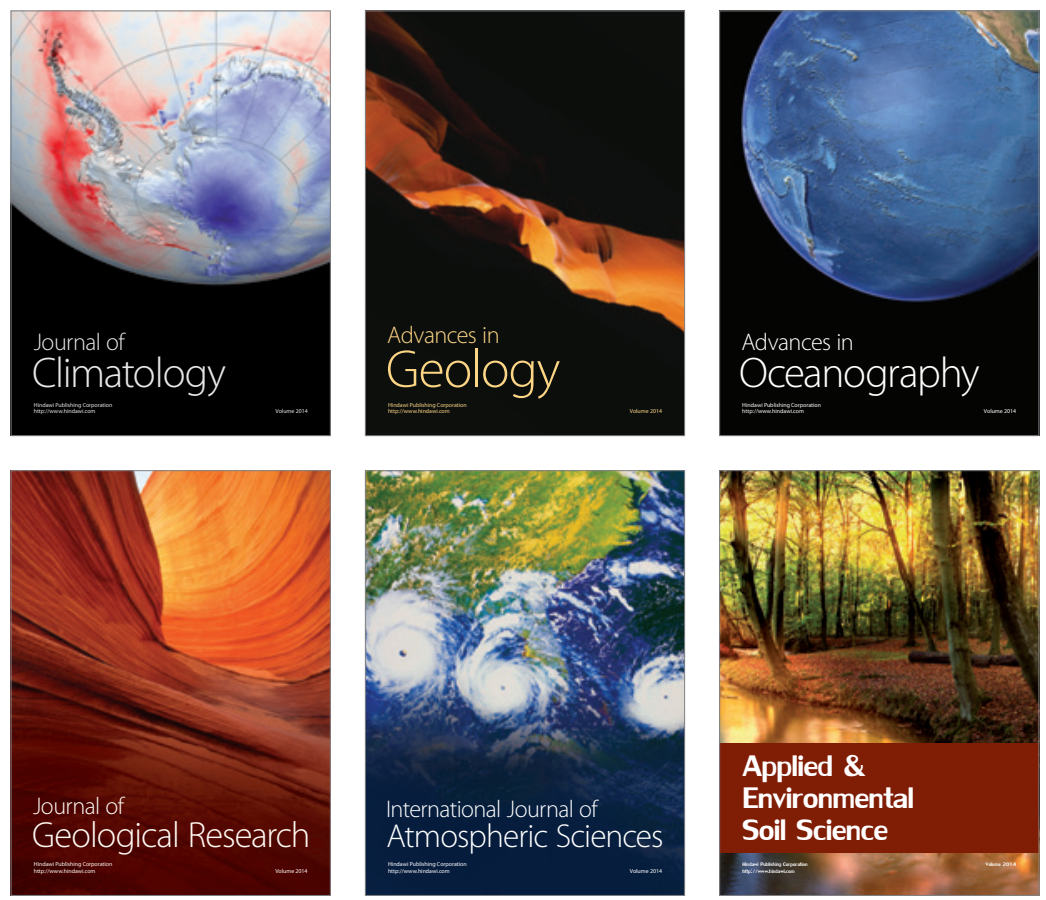
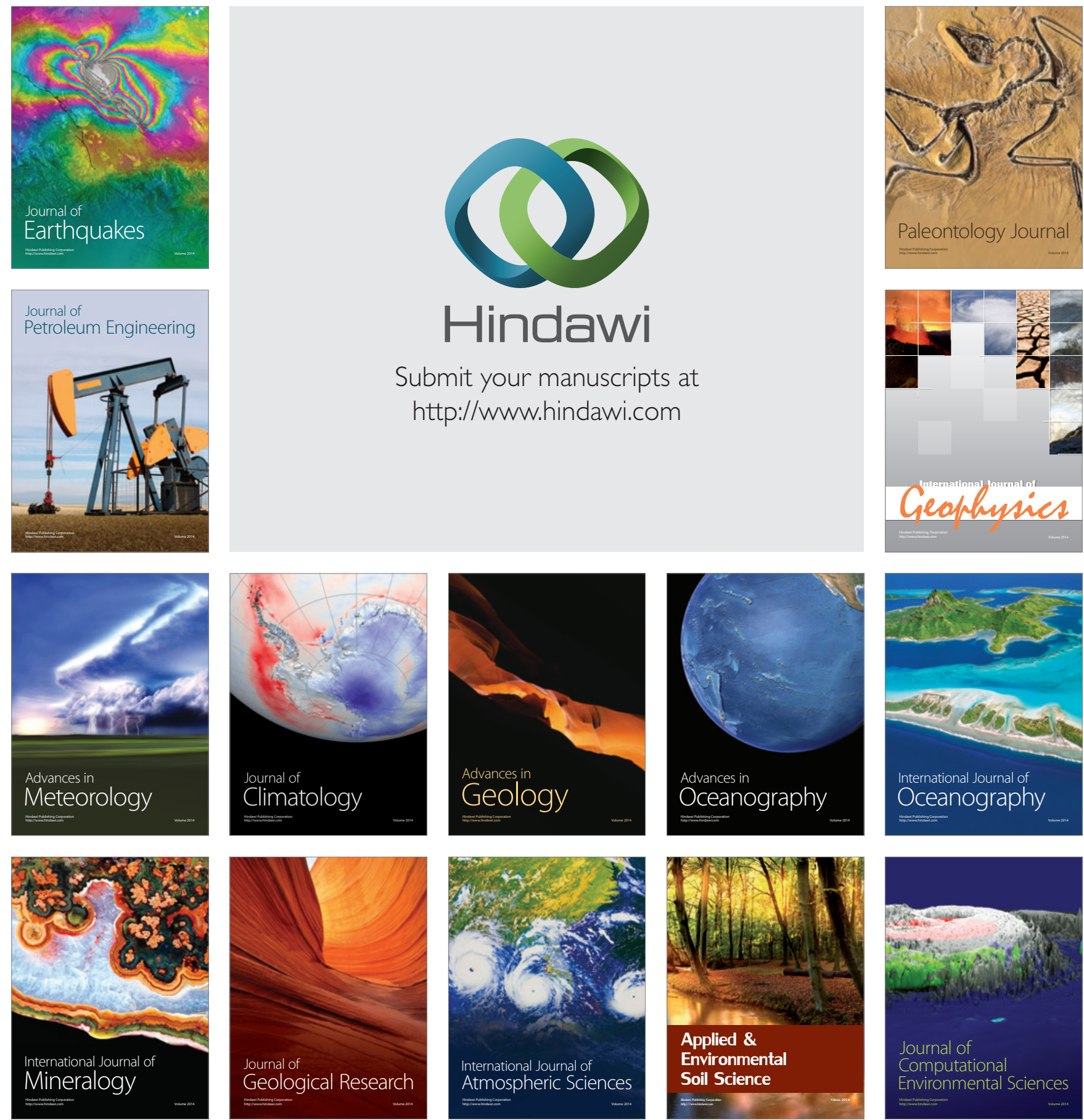